\title{
The Internet in the reproductive health care sector: good or bad?
}

\section{Susan Quilliam}

Writer, Broadcaster, Consultant and Trainer, Cambridge, UK

\section{Correspondence to}

Ms Susan Quilliam; susan@susanquilliam.com http://www.susanquilliam.com

Received 28 January 2013 Accepted 28 January 2013
To cite: Quilliam S. Journal of Family Planning and Reproductive Health Care 2013:39:139-141.

\section{BACKGROUND}

Cast your minds back to 1 January 1983. We didn't know it at the time, but on that day a global change began that would have a seismic impact on the work we do. I am of course talking about the Internet, which is 30 years old this year.

To celebrate this anniversary, I'm casting an eye over this technological advance that is now such an integral part of most Journal readers' lives. Thirty years on, it's surely worthwhile to look at where we've arrived and see if it's a good place.

I must admit that until recently I wasn't completely convinced. In a 2007 column I wrote for this Journal, I reported on how patients' use of the Internet was causing health professionals some angst. ${ }^{1}$ There was frustration at the number of hefty printouts brandished in the consulting room, defensiveness at having to counterbalance inaccurate or alarmist Internet health coverage, and wariness of how undiscriminating patients were in their use of the World Wide Web (the 'Web').

That said, from my investigations, patients seemed to be completely in favour. The Internet gave them the ability to $\log$ on $24 / 7$ - and in their pyjamas, if they so wished. It gave them a wide variety of information and support. It gave them (or rather they believed it gave them) relevance; the Internet was seen to offer a topicality that the slow pace of print media could not offer, and if sometimes the facts and figures were less than accurate, patients were not too aware of that issue.

Now, in 2013, it's clear that all of us professionals as well as patients - are persuaded. Our increased positivity about the Internet is not just down to the fact of being more at ease with it and thus less wary; it's that we are now so dependent on the Web that we willing to cope with its downsides, and are gradually learning to compensate for them. But I feel it is still worth asking the question: When it comes to our arena, and when it comes to our patients, is the Internet a good idea?

\section{ACCESSIBILITY AND}

\section{CONFIDENTIALITY}

It's undeniable that the Web has brought the world - and the medical world - into patients' homes and into their personal lives. They no longer have to travel to a library or bookshop to obtain information about medical conditions and healthy lifestyle choices. They no longer have to book a consultation with a medical professional to explore family planning options or learn about infertility treatments. They can now get at least headlines on these topics not only from their desk but from their phone or tablet, at any time and in almost any location worldwide, with growing reliability, increasing cost-effectiveness and at the speed of light.

And, they get all this confidentially. I wonder if we health professionals underestimate this benefit of the Web. I work with several websites that offer personalised advice via e-mail, and the correspondence I receive regularly contains phrases such as "I can't talk about this to ...", "I'm embarrassed to ask but ...", "... and so I'm writing to you", and so on.

Of course for every such worried teenager (or pensioner, for it's not just young people who need privacy), there will be several dozen who attend their general practitioner (GP) or family planning clinic (FPC) without hesitation. But the confidentiality that the Web brings ensures that those who do hesitate about approaching health professionals for advice and information have somewhere to go.

\section{PROMOTION AND SERVICES}

In fact, such individuals have many places to go, and an increased ability to find those places. Surely every organisation in our field, whether large or small, now has an online presence. To name only a 
few based in Britain - though of course every website offers worldwide coverage - we have the Family Planning Association (fpa), Brook, the Sexual Advice Association, Women's Health Concern, The Menopause Society, plus an endless array of condition-specific sites for everything from antenatal care to the wart virus. Add to this the fact that almost every individual GP surgery and every FPC has an online presence, and patients can now instantly track down local and global services in a way that was unthinkable even a few years ago.

Plus, sites offer a cornucopia of services. For this article I carried out a short review of the abovementioned organisational sites in Britain, three international ones [Kinsey Confidential (the Kinsey Institute's patient site), the World Association of Sexology, and Planned Parenthood] and a sample of district-based surgeries and clinics. What follows is a list of what I found on offer, with the caveat that I will have certainly omitted several categories of service.

Information presented as research, as case studies, as magazine-type features, via quizzes, questionnaires, blogs and podcasts. Professional advice presented as all of the above, plus in 'agony aunt' format, and via e-mail response as well as Web-accessed phone and Skype support. Tools for health assessment, lifestyle evaluation, symptom checking, finding a clinic, making an online booking. Targeted areas for parents, for teenagers, for health professionals, for press. Peer support in the form of forums, chat rooms and local groups. Campaigns organised online with special features to support volunteers and fundraisers. And, last but by no means least, 'apps' to give feedback if health providers don't live up to expectations.

\section{RELIABILITY AND QUALITY CONTROL}

So far, so wonderful - and certainly what is now on offer is increasingly wider and deeper. But is it sufficiently dependable? The Internet has always suffered from a lack of accuracy; its very freedom means that no one is truly able to monitor it, and the bigger it gets the less possible seems any detailed form of surveillance. Particularly when sexual health websites worldwide are launched not only by organisations but also by individual clinicians, there is increasing room for errors, if not deliberate misuse.

So there are still huge questions with regard to reliability and not just because, as I wrote in my 2007 article, Web writers so often tend to "summarise ... delete ... adapt ... distort". ${ }^{1}$ They now, with the rise of personal blogs, also argue, persuade, attack, defend, add spin, and season the whole with large dollops of emotional bias. I have had e-mail adviceseekers report that they are writing to me because having posted a sexual health question on a public forum they were roundly 'trolled' for their self-revelation.
That said, quality control is now on the agenda in a way it wasn't a few years ago. Not only is there more informal responsibility taken - few individuals or organisations now launch sexual information or advice websites without checking facts and figures but also formal initiatives such as the English Information Standard Scheme are increasingly being used to quality control provision. Also, the ease of communication on the Internet means an increased ability for individuals and organisations to co-operate and so self-improve. One example of this is NHS Choices, which recently held a consultancy exercise involving nearly 700 patient organisations to inform the site direction. ${ }^{2}$

\section{USER EDUCATION}

All these Web benefits, however, clearly mean nothing if Internet consumers themselves are not using the system wisely. And here they may be severely hampered by the exponential growth of the Web. Recent comment on Internet usage concludes that there is so much information out there that even the most aware users may get confused and make bad decisions. Google the words 'sex advice' - as users typically might do if they want advice on sex - and you get 386 million results, many of which add the word 'hot' to the phrase. It's therefore understandable that users might be accessing not necessarily the best sites but those that have the best search engine optimisation.

However, I'm now much more confident about consumer wisdom than I have been in the past. For society as a whole has moved speedily up the learning curve of new technology and is now far more aware of the possible dangers and caveats. I suspect that patients now more often search and cross-check several sources for information on any particular topic. They are now more likely to recognise the names of key sexual health organisations and rely on them more than they do on random or non-accredited sites. And they now tend to spot if a website is sponsored by a commercial organisation, and be more likely to take from such a site the extremely useful guidelines and advice without necessarily feeling that they need to buy the product being advertised.

Quite simply, as with most advances in society, over time individuals are learning how to make distinctions, discriminate, avoid the bad and seek out the good, the useful, the genuine. They are also learning how to support others to do the same; one of the benefits of Internet feedback forms, forums and chat rooms is the ease with which Web users can directly critique an erroneous website, as well as warn others off using it. And, through this process, surely they are also learning to be more informed and more confident, more proactive, more responsible, and more able to work with health providers, complying and co-operating in a way that benefits both sides. 


\section{A FINAL QUERY}

So, despite concerns about reliability, by making health provision more accessible and confidential, by promoting health provision more successfully, by offering a wider range of services and support, and by increasing patient-professional partnership, surely the Internet is undeniably proving its worth.

But one question remains before I give my unqualified approval. What about the way in which the Internet steadily funnels users away from personal interaction and into online interaction? There have been many general criticisms of this trend, from those who claim that young people never 'talk' nowadays, to those who point out that Internet porn is leading to a toxic dissatisfaction with 'real-life' partnerships.

Are these criticisms relevant to the health arena? Are we facing a time when personal interaction between health professional and patient suffers? In a further 30 years will patients simply never bother to enter a GP surgery because they are getting their information, their support - and indeed, as is already offered on some sites, their diagnosis and medication - via the Web? Just as the bookshop Borders and record shop HMV have disappeared from the high street because they've been overtaken by Internet outlets, will our clinics close because of some Amazon equivalent in the family planning sector?

I don't believe we need to panic. Yes, patients do use health websites as triage for minor conditions, but those websites almost always guide them into visiting the surgery where necessary. And yes, patients do use the Internet to provide further information and support for major conditions, but they know very well that initially, at least, those major conditions need specialist consultation.

And I have another reason for believing that that the Internet will never replace the health professional. Quite simply, human beings will never stop needing human contact. Patients don't only need information, however accurate. They don't only need e-mail or Skype support, however well done. When people are ill - indeed especially when they are ill - they need an experienced, compassionate, hands-on clinician not only to examine, to diagnose and to treat, but also to comfort them.

So my final judgement is a positive one. The Internet is every day making our jobs a little easier, yet it's my own personal belief that it will never put us out of a job.

Funding None.

Competing interests None.

Provenance and peer review Commissioned; internally peer reviewed.

Author's note The author is the resident psychologist for the Sexual Advice Association and part of her role entails offering e-mail advice to their users on an unpaid, voluntary basis.

\section{REFERENCES}

1 Quilliam S. Remember 1967? We do.... J Fam Plann Reprod Health Care 2007;33:215-216.

2 Quilliam S. "Join us in making voices heard": NHS Choices 5 years on. J Fam Plann Reprod Health Care 2012;38:56-58.

\section{READERS' CONTRIBUTIONS INVITED ON 'A BETTER WAY OF WORKING'}

The Journal publishes occasional 'A Better Way of Working' articles, the purpose of which is to disseminate service delivery suggestions likely to be of interest and relevance to the Journal's readership. Readers are invited to submit suggestions based on their own personal experience for consideration by the Journal Editor. Contributions normally should not exceed 1000 words and should be written in a standardised format responding to the following four questions (or similar): Why was change needed? How did you go about implementing change? What advice would you give to others who might be considering a similar course of action? How did you show that the change had occurred? All contributions should be submitted via the Journal's online submission system at http://mc.manuscriptcentral.com/jfprhc. 